\title{
Non-coding RNAs as regulators in epigenetics (Review)
}

\author{
JIAN-WEI WEI ${ }^{*}, \mathrm{KAI} H \mathrm{HANG}^{*}, \mathrm{CHAO}$ YANG $^{*}$ and CHUN-SHENG KANG \\ Department of Neurosurgery, Tianjin Medical University General Hospital, Laboratory of Neuro-Oncology, \\ Tianjin Neurological Institute, Key Laboratory of Post-trauma Neuro-repair and Regeneration \\ in the Central Nervous System, Ministry of Education, Tianjin Key Laboratory of Injuries, \\ Variations and Regeneration of the Nervous System, Tianjin 300052, P.R. China
}

Received June 12, 2016; Accepted November 2, 2016

DOI: $10.3892 /$ or.2016.5236

\begin{abstract}
Epigenetics is a discipline that studies heritable changes in gene expression that do not involve altering the DNA sequence. Over the past decade, researchers have shown that epigenetic regulation plays a momentous role in cell growth, differentiation, autoimmune diseases, and cancer. The main epigenetic mechanisms include the wellunderstood phenomenon of DNA methylation, histone modifications, and regulation by non-coding RNAs, a mode of regulation that has only been identified relatively recently and is an area of intensive ongoing investigation. It is generally known that the majority of human transcripts are not translated but a large number of them nonetheless serve vital functions. Non-coding RNAs are a cluster of RNAs that do not encode functional proteins and were originally considered to merely regulate gene expression at the posttranscriptional level. However, taken together, a wide variety of recent studies have suggested that miRNAs, piRNAs, endogenous siRNAs, and long non-coding RNAs are the most common regulatory RNAs, and, significantly, there is a growing body of evidence that regulatory non-coding RNAs play an important role in epigenetic control. Therefore, these non-coding RNAs (ncRNAs) highlight the prominent role of RNA in the regulation of gene expression. Herein, we summarize recent research developments with the purpose of coming to a better understanding of non-coding RNAs and their mechanisms of action in cells, thus gaining a preliminary understanding that non-coding RNAs feed back into an epigenetic regulatory network.
\end{abstract}

Correspondence to: Professor Chun-Sheng Kang, Department of Neurosurgery, Tianjin Medical University General Hospital, 154 Anshan Road, Heping, Tianjin 300052, P.R. China

E-mail: kang97061@tmu.edu.cn

${ }^{*}$ Contributed equally

Key words: epigenetics, non-coding RNAs, DNA methylation, histone modification

\author{
Contents \\ 1. Introduction \\ 2. SiRNA \\ 3. miRNA \\ 4. piRNA \\ 5. IncRNA \\ 6. Conclusion and prospective
}

\section{Introduction}

Epigenetics is the study of inherited changes in phenotype (appearance) or gene expression that are caused by mechanisms other than changes in the underlying DNA sequence $(1,2)$. These changes may persist through multiple cell divisions, even for the remainder of the cell's life, and may also last for multiple generations. However, to reiterate, there is no change in the underlying DNA sequence of the organism. The most significant epigenetic mechanisms include DNA methylation, histone modifications, and the processes mediated by the most recently discovered class, the non-coding RNAs (3). DNA methylation is defined as the selective methylation (addition of a methyl group) of cytosine within a $\mathrm{CpG}$ dinucleotide, thereby forming 5 -methylcytosine $(4,5)$. There are two types of DNA methyltransferases (DNMTs). The first type, DNMT1, mainly plays a role in the maintenance of methylation, can methylate the hemi-methylated cytosine in double-stranded DNA molecules, and may be involved in the methylation of the newly synthesized strand during replication of duplex DNA (6). However, DNMT3a and DNMT3b play a major role in de novo methylation, in which methylation can be performed on double-stranded DNA that is not methylated. DNA methylation is generally associated with gene silencing (7), and DNA demethylation is usually connected with gene activation (8-10).

Histone modification is the process of modification of histone proteins by enzymes, including post-translational modifications, such as methylation, acetylation, phosphorylation, and ubiquitination. These modifications constitute a rich 'histone code' (11). Histone modifications play a vital role in gene expression by modulating the degree of tightness, or compaction, of chromatin (12). Methylation, which frequently occurs on histones H3 (13) and H4 on specific lysine (K) and 
arginine (A) residues, is one important method for the modification of histone proteins. Histone lysine methylation can lead to activation and can also lead to inhibition, usually depending on the situation in which it is located. For instance, H3K9, H3K27, and H4K20 are well known by scholars as important 'inactivation' markers, i.e., repressive marks, because of the relationship between these methylations and heterochromatin formation. However, the methylation of H3K4 and H3K36 are considered to be 'activation' marks $(14,15)$. Acetylation, which in most cases occurs in the N-terminal conserved lysine residues, is also an important way to modify the histone proteins, for example, acetylations of lysine residues 9 and 14 of histone H3 and of lysines 5, 8, 12, and 16 of histone H4. Both acetylations are associated with the activation or opening of the chromatin. On the contrary, de-acetylation of the lysine residues leads to chromatin compression and inactivation of gene transcription. Different histone modifications can affect each other and can have interactions with DNA methylations $(16,17)$.

Non-encoding RNAs (non-coding RNAs) that are not translated into proteins can be divided into housekeeping non-coding RNAs and regulatory non-coding RNAs. RNA that has a regulatory role is mainly divided into two categories based on size $(18,19)$ : short chain non-coding RNAs (including siRNAs, miRNAs, and piRNAs) and long non-coding RNA (lncRNAs) (Table I). In recent years, a large number of studies have shown that non-encoding RNAs play a significant role in epigenetic modification and can regulate expression at the level of the gene and the level of chromosome to control cell differentiation (20-23) (Fig. 1). Therefore, in this review we will focus on the above four kinds of non-coding RNAs and their regulatory roles in epigenetics.

\section{SiRNA}

siRNA is derived from long double-stranded RNA molecules (including RNAs arising from virus replication, transposon activity or gene transcription), which can be cut by the Dicer enzyme into RNA fragments of 19-24 nt (nt: nucleotides), with the resulting RNA fragments exercising their functions when loaded onto Argonaute (AGO) proteins $(24,25)$, as summarized in Fig. 2B. (also indicate Fig. 2A appropriately)

Recent studies showed that siRNA can lead to transcriptional gene silencing (TGS) in cells by means of DNA methylation and histone modification in cells (26-28). Zhou et al (29) demonstrated that siRNA could silence EZH2 and then reverse cisplatin-resistance in human non-small cell lung and gastric cancer cells. EZH2, as a histone methyltransferase, can cause H3K27 methylation, and then the methylated $\mathrm{H} 3 \mathrm{~K} 27$ can serve as an anchor point for CpG methylation, leading to the formation of silent chromatin, and ultimately, to TGS (30). Chromatin immunoprecipitation experiments showed that the binding of DNMTs to a given gene inhibited by EZH2 depended on the presence of EZH2. Bisulfite sequencing results also proved that $\mathrm{EZH} 2$ was required for the methylation of an EZH2-repressed target promoter, suggesting that EZH2 participated in DNA methylation by way of recruiting a DNA methyltransferase.

Several teams have demonstrated that depletion of Dicer, Argonaute, and RNA-dependent RNA polymerase homolog Rdpl (the key components of the RNA interference silencing

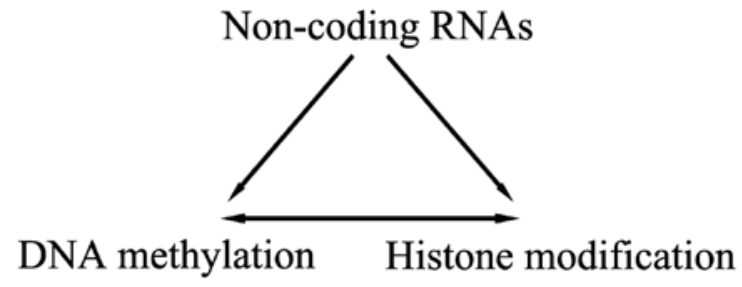

Figure 1. Function of non-coding RNAs in epigenetics.

complex, RISC) can cause the aberrant accumulation of long non-coding RNAs, resulting in the loss of H3K9me, thus impairing centromere function $(31,32)$. siRNA-mediated epigenetic regulation is also found in Arabidopsis (33), in which case $\mathrm{AGO} 4$, a specific argonaute family protein, is required for siRNA accumulation and DNA and histone methylation (34). Consistent with these results, $\mathrm{H} 3 \mathrm{~K} 9$ me-marked pericentric heterochromatin is maintained by an RNA component (35). Moreover, with the development of sequencing technology, our efforts bring to light the forceful correlation between H3K9 methylation and repetitive elements (36), which occupy two-thirds of the human genome. These outstanding findings bring us an intriguing possibility that the RNA interference pathways may have impressive roles in maintenance and regulation of the epigenome. Deep mechanistic research of the siRNAs involved in this process may contribute to helping us accurately understand the inheritance of epigenetic regulation.

\section{3. miRNA}

miRNAs are single-stranded RNAs of approximately 19-24 nt, of which 50\% are located in chromosomal regions that are prone to structural changes (37). Originally, it was thought that there were two main points of difference between siRNA and miRNA as classes of regulatory RNAs. One is that miRNA is endogenous and is the expression product of the biological gene but that siRNA is exogenous, originating from viral infection, the point of gene transfer, or the gene target. The other point of difference is that miRNA consists of incomplete hairpin-shaped double stranded RNA, which is processed by Drosha and Dicer, whereas siRNA is the product of a fully complementary, long double-stranded RNA, which is processed by Dicer (38). In spite of these differences, it is speculated that miRNA and siRNA have a similar mechanism of action in mediating transcriptional gene silencing because of the close relationship between miRNA and siRNA, e.g., the size of the two fragments are similar (Fig. 2). Recently, in the human genome, almost 1,800 putative miRNAs have been identified, and the number of miRNAs is still increasing rapidly due to the development of high-throughput sequencing technologies (39-41).

The current model is that the regulatory mechanism of miRNA reflects the degree of complementarity between the specific loading protein AGO, a given miRNA, and the target mRNA (42). Usually only a very small number of miRNAs are almost completely complementary with their mRNA targets; in this case, a targeted mRNA can be directly cleaved and degraded. However, the overwhelming number of miRNAs and their target mRNAs are only partially complementary, 
Table I. Main non-coding RNAs in regulation of epigenetics.

\begin{tabular}{llll}
\hline Name & Size & Source & Main functions \\
\hline siRNA & $19-24 \mathrm{bp}$ & Double stranded RNA & Silent transcription gene \\
miRNA & $19-24 \mathrm{bp}$ & pri-miRNA & Silent transcription gene \\
piRNA & $26-31 \mathrm{bp}$ & Long single chain precursor & Transposon repression \\
& & & DNA methylation \\
lncRNA & $>200 \mathrm{bp}$ & Multiple ways & Genomic imprinting \\
& & & X-chromosome inactivation \\
\hline
\end{tabular}

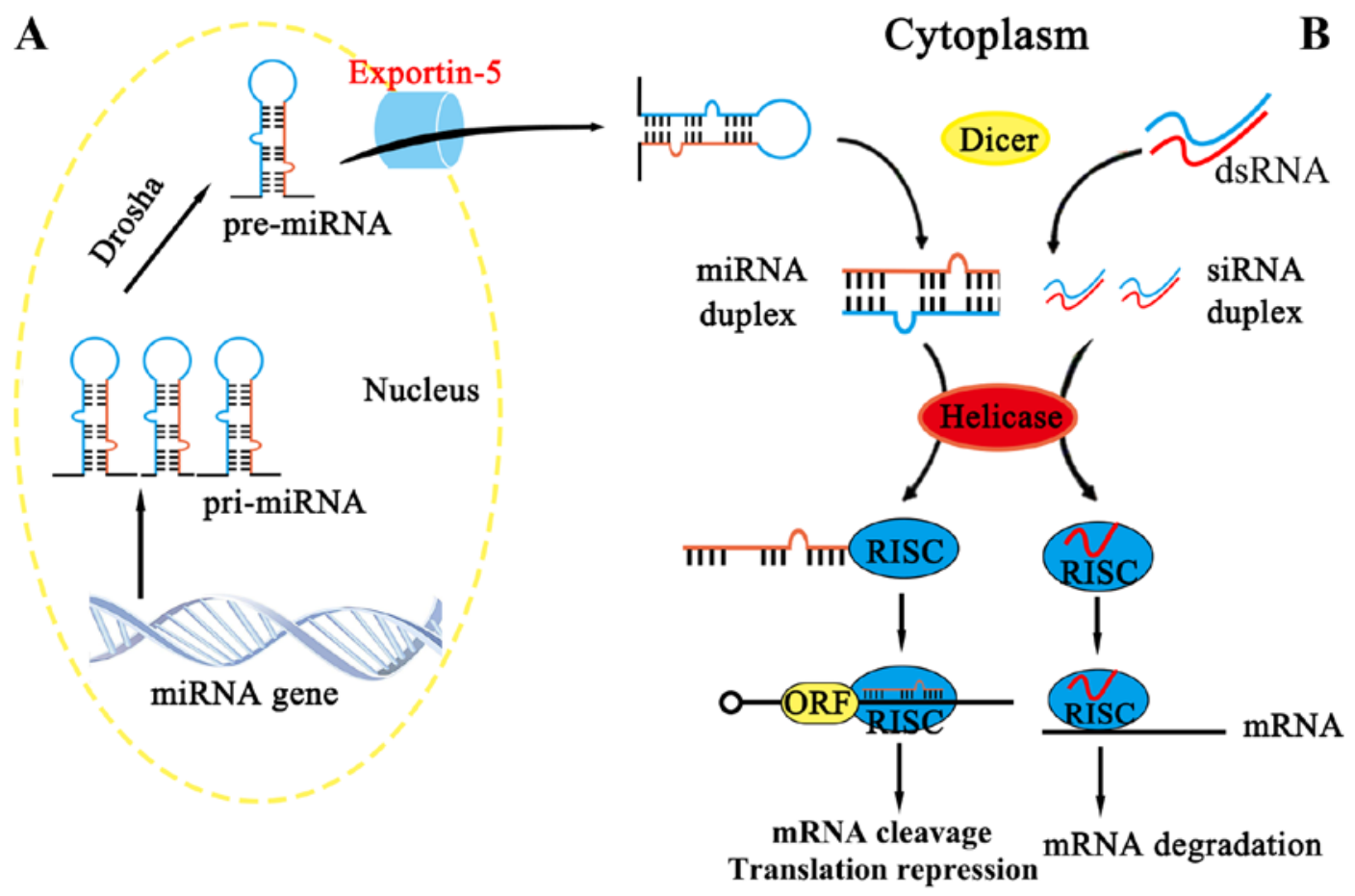

Figure 2. The mechanism of miRNA and siRNA. (A) miRNA is produced by endogenous genes containing hairpin structures of 65-70 nt pre-miRNA; the hairpin structure was processed by Drosha-DGCR8 complex into pre-miRNA in the nucleus, transferred to cytoplasm through Exprotin-5, then processed into miRNA by Dicer, and loaded to protein Argonaute (AGO2). (B) siRNA derived from the long double stranded RNA molecule was cut into a fragment of 21-25 nt by the Dicer enzyme and then played a role after loading to protein Argonaute (AGO2).

generally for 6-7 nucleotides, which are located in the 5' end of the 2 to 7 nucleotide stretch called the 'seed region'. The 'seed region' is the most basic and decisive factor in the selection of the target because of the seed region's important role in the binding of the target. At the same time, many studies suggest that a given miRNA can regulate even hundreds of different genes (42-44). Through the study of more than 13,000 human genes, Lewis et al (44) made a further speculation: that histone methyltransferases, methyl $\mathrm{CpG}$ binding proteins, chromatin domain proteins, and histone deacetylases are potential targets for miRNAs.

Although miRNAs that directly participate in epigenetic regulation have not been reported in mammalian cells, several scholars have found that aberrant expression of miRNAs can change the whole DNA or chromatin state by restricting chromatin remodeling enzyme activity $(45,46)$. Existing studies have shown that miRNAs can induce chromatin remodeling through the regulation of histone modification. Some scholars have reported that histone deacetylase 4 (HDAC4) is a specific target for $m i R-140$ in mouse embryonic cartilage tissue. These two examples suggest that miRNA may be involved in TGS via the modification of histone proteins (47). Kim et al (48) found that $m i R-320$, one of the most conserved miRNAs, can recruit AGO1 to the POLR3D promoter. Moreover, EZH2 and H3K27 trimethylation are involved in TGS. This further confirms that miRNAs can cause TGS.

Considering the large number of miRNAs that base pair with transcribed RNAs, it is not surprising that the miRNA class of noncoding RNAs may directly take part in epigenetic control of gene expression. Two current studies demonstrated the existence of miRNA-mediated DNA methylation changes in plants $(49,50)$. Other recent studies have shown that miRNA can affect DNA methylation through the regulation of DNA methylases. Fabbri et al (51) found that the expression of the $m i R-29$ family ( $m i R-29 a, m i R-29 b$ and $m i R-29 c$ included) is downregulated but that DNMT3a and DNMT3b are highly 
expressed in non-small cell carcinoma. The complementarity between the miR-29 family and the 3'UTRs of DNMT3a and $3 \mathrm{~b}$ suggests that mRNAs of DNMTs are the target of the miR-29 family.

Benetti et al (52) and Sinkkonen et al (53) both demonstrated that the downregulation of DNMT3a and 3b activity depended on the $m i R-29$ family in mouse embryonic stem cells lacking Dicer. In this case, the main mechanism for the absence of DNA methylation was that retinoblastomalike protein 2 (Rbl2) inhibited the activity of DNMT3a and DNMT3b. Rbl2 can be inhibited by the miRNA-29 family, but the miRNA-29 family was downregulated in the absence of Dicer activity. These observations also raise the possibility that $m i R-29$ can inhibit tumors by enhancing the expression of tumor suppressor genes. Work by Gonzalez et al (54) shows that tumor miRNAs (miR $17-5 p$ and $m i R-20 a$ ) have the ability to induce the formation of heterochromatin, providing another example of the existence of new mechanisms of chromatin remodeling and gene transcription mediated by miRNA regulation. The above-mentioned kinds of research will help us to clarify the mechanisms of tumorigenesis and broaden our perspective of what may constitute promising new targets for cancer therapy.

\section{4. piRNA}

piRNAs are a class of RNA molecules that are approximately 26-31 nt in length. The name, piRNA (Piwi-interacting RNA), reflects the fact that piRNAs bind to Piwi proteins under physiological conditions $(55,56)$. Reflecting its role as an epigenetic regulatory factor, the Piwi protein silences the homeobox gene by binding to genomic PcG response elements together with PcGs (polycomb group proteins). Thus, it has been speculated that the piRNAs that are associated with the Piwi protein should also have important roles in epigenetic regulation (57).

Relevant research shows that piRNAs can be divided into two sub-clusters $(58,59)$. One is the pachytene piRNA cluster, which mainly occurs during meiosis and continues to be expressed up through the haploid spermatid stage. The other is the pre-pachytene piRNA cluster, which appears mainly in premeiotic germ cells. Although pre-pachytene piRNAs have the molecular characteristics of the pachytene piRNA cluster, pre-pachytene piRNAs come from a completely different cluster and contain repetitive sequence elements.

The biosynthesis and mechanism(s) of action of the piRNA class of regulators are still unclear at present. Each piRNA comes from a single chain precursor, rather than from a double-stranded RNA, implying that the functions of piRNAs do not depend on Dicer enzyme activity in cells. Another difference is the feature of strand asymmetry in the pachytene piRNA cluster (60). Consequently, there are two emerging hypotheses: one is that each piRNA is generated from a long single-stranded molecule, and the other hypothesis is that the piRNA may serve as a primary transcript. Aravin et al (58) proposed a model of piRNA self-amplification in cells based on experimental evidence in rats. It is different from the amplification model in Drosophila, in which the gene cluster is not posited to be the main source of the primary piRNAs. Instead, the primary piRNAs are thought instead to be produced by transposon mRNAs in amplification cycles.
In contrast to gene-silencing mediated by small RNAs, piRNAs were originally found to have the ability to promote euchromatic histone modifications in Drosophila melanogaster (61). Moreover, a current genome-wide survey indicates that piRNAs and Piwi are strongly associated with chromatin regulation and that piRNAs efficiently recruit the HPla protein to specific genomic loci in order to repress RNA polymerase II transcription (62). Studies have shown that the DNA methyltransferase family (DNMT3a, DNMT3b, and DNMT3L) plays a major role in transposon methylation. Thus, the catalytic activities of DNMT3a and DNMT3b are very important in germ cells and somatic cells, while DNMT3L is a key promoter of methylation in germ cells (63). Experiments show that two Piwi proteins, MILI and MIWI2, are necessary for silencing LINE- 1 and IAP transposons in the testis and the deletion of MILI or MIWI2 reduces the level of transposon methylation; MIWI2 is always located in the nucleus during the critical period of methylation; small RNA sequence analysis showed that MILI and MIWI2 both have a role upstream of DNMT3L and then act on DNMT3a and DNMT3b. The above experimental results confirmed that the complex of Piwi protein/ piRNA can mediate the methylation of transposons and that piRNA is a specific determinant of DNA methylation in germ cells (64). A similar regulatory mode may also exist in other kinds of somatic tissues, but this notion still remains unclear.

\section{IncRNA}

LncRNAs represent another class of non-coding regulatory RNAs. LncRNAs are generally $>200 \mathrm{nt}$ in length, are located in the nucleus or cytoplasm, and rarely encode proteins $(65,66)$. LncRNAs usually can be divided into five categories: Sense, Antisense, Bidirectional, Intronic, and Intergenic IncRNA (19). However, these five categories mainly involve only four archetypal lncRNA mechanisms for regulating gene expression: Signals, Decoys, Guides, and Scaffolds (67).

There are many different sources of IncRNAs (19): (I) Arising by the disruption of the translational reading frame of a protein-encoding gene (II); Resulting from chromosomal reorganization, for example, by the joining of two non-transcribed DNA regions in such a fashion as to promote transcription of the merged, non-coding sequences; (III) Produced by replication of a non-coding gene by retrotransposition; (IV) Generation of a non-encoding RNA containing adjacent repeats via a partial tandem duplication mechanism; and (V) Arising from the insertion of a transposable element(s) into a gene in such a way as to produce a functional, transcribed non-encoding RNA. Studies have indicated that lncRNAs play a similar role in the regulation of gene expression in spite of fact that there is no common, shared mechanism by which all the numerous lncRNAs originated (65).

Studies of genomic imprinting and $\mathrm{X}$ chromosome inactivation were the first to reveal a role for IncRNAs in epigenetic regulation, identifying roles for two lncRNAs, H19 RNA and Xist RNA, respectively (68). H19 is a genomic imprinting lncRNA that can be transported to the cytoplasm, is spliced and polyadenylated, and achieves a high cytosolic concentration. The function of H19 is still not clear, even if it is the first gene to be associated closely with genomic imprinting. Recently, H19 RNA was found to contain a precursor of 
miR-675 in human and rat cells (69), indicating that H19 RNA may also regulate gene expression through a miRNA-based mechanism. Genomic imprinting is associated not only with the $H 19$ gene cluster, but also with Kcnqlot1, Air, and Nespas lncRNAs $(70,71)$. Experimental results of promoter deletion in Kcnqlotl and Air suggest that lncRNA transcripts are necessary for silencing Kcnqlotl-and lgf2r/Air-imprinted genes and that they are essential for the methylation of H3K27 and H3K9 and for DNA methylation of some genes (72).

Xist RNA, which is a $17 \mathrm{~kb}$ long non-coding RNA, is very important for $\mathrm{X}$ chromosome inactivation. Xist does not travel to the cytoplasm; instead, this RNA interacts physically with the $\mathrm{X}$ chromosome that is about to be inactivated by Xist. Xist RNA silences genes in cis by 'coating' the surface of the inactivated X chromosome (73). Recent research by Zhao et al (74) shows that RepA (a $1.6 \mathrm{~kb}$ fragment of Xist RNA) can induce $\mathrm{H} 3 \mathrm{~K} 27$ trimethylation by recruiting the Polycomb repressive complex 2 (PRC2) to the inactivated X. In addition, RepA has a crucial importance not only for methylation of H3K27 but also for expression of Xist RNA.

Recent studies show that some gene clusters and lncRNAs may have dual roles, participating both in the process of $\mathrm{X}$ chromosome inactivation and in the process of genomic imprinting. In this context, gene silencing may involve both cis and trans mechanisms. For instance, the HOTAIR RNA (Hox transcript antisense RNA) originates from the HOXC cluster and can silence gene transcription in a region of up to $40 \mathrm{~kb}$ in $H O X D$; the main mechanism is through recruitment of Polycomb repressive complex PRC2 to $H O X D$ through HOTAIR, which then triggers the formation of heterochromatin and TGS via trimethylation of H3K9 (75-77).

Other studies (78) indicate that there is another mechanism of $\mathrm{X}$ chromosome inactivation. According to this mechanism, Xist and Tsix can form an RNA dimer that is processed by Dicer to yield siRNAs. These different approaches may be able to coordinate the roles of lncRNAs and small RNAs in chromatin remodeling, indicating that there is a more complex and interactive network of regulation by non-coding RNAs.

\section{Conclusion and prospective}

With the attention on non-coding RNAs in the etiology of diseases, the noncoding RNA has become a 'hot' issue in modern genetics research, especially as a new mechanism of epigenetic regulation. However, thus far, scientists have only a very limited understanding of the mechanisms by which noncoding RNAs regulate gene expression.

At first, piRNAs, miRNAs and siRNAs were thought to function independently, and this supposition was reinforced by the obvious differences between them. However, in recent years, the roles of these pathways have begun to blur, and some of these pathways appear to interact, thereby constituting a regulatory network. So how have living organisms adapted to these multiple regulatory mechanisms? Before we can solve this problem, we must first understand the details of the non-coding RNAs themselves. At present, a key problem is the respective roles and interrelationships between this large, complex RNA regulatory network and protein-based regulatory mechanisms. Analysis of this regulatory network for non-coding RNAs is very difficult work, so we need to systematically find and analyze non-coding RNAs. This will require gradual improvements and new methods in gene and genome scanning technologies to reveal all the information and functions of non-coding RNAs. The ultimate goal is to clarify the detailed mechanisms of regulation by the non-coding RNAs and their interactions with normal cells and disease states.

\section{Acknowledgements}

This work was supported by the National High Technology Research and Development Program 863 (2014AA021102), China National Natural Scientific Fund (81372703, 81572932).

\section{References}

1. Egger G, Liang G, Aparicio A and Jones PA: Epigenetics in human disease and prospects for epigenetic therapy. Nature 429: 457-463, 2004.

2. Bird A: Perceptions of epigenetics. Nature 447: 396-398, 2007.

3. Peschansky VJ and Wahlestedt C: Non-coding RNAs as direct and indirect modulators of epigenetic regulation. Epigenetics 9: 3-12, 2014.

4. Goll MG and Bestor TH: Eukaryotic cytosine methyltransferases. Annu Rev Biochem 74: 481-514, 2005.

5. Bird A: DNA methylation patterns and epigenetic memory. Genes Dev 16: 6-21, 2002.

6. Weber M, Hellmann I, Stadler MB, Ramos L, Pääbo S, Rebhan M and Schübeler D: Distribution, silencing potential and evolutionary impact of promoter DNA methylation in the human genome. Nat Genet 39: 457-466, 2007.

7. Okano M, Bell DW, Haber DA and Li E: DNA methyltransferases Dnmt3a and Dnmt3b are essential for de novo methylation and mammalian development. Cell 99: 247-257, 1999.

8. Berger SL: The complex language of chromatin regulation during transcription. Nature 447: 407-412, 2007.

9. Bernstein BE, Meissner A and Lander ES: The mammalian epigenome. Cell 128: 669-681, 2007.

10. Goldberg AD, Allis CD and Bernstein E: Epigenetics: A landscape takes shape. Cell 128: 635-638, 2007.

11. Harr JC, Gonzalez-Sandoval A and Gasser SM: Histones and histone modifications in perinuclear chromatin anchoring: From yeast to man. EMBO Rep 17: 139-155, 2016.

12. Jenuwein T and Allis CD: Translating the histone code. Science 293: 1074-1080, 2001.

13. Lu C, Jain SU, Hoelper D, Bechet D, Molden RC, Ran L, Murphy D, Venneti S, Hameed M, Pawel BR, et al: Histone H3K36 mutations promote sarcomagenesis through altered histone methylation landscape. Science 352: 844-849, 2016.

14. Mellor J, Dudek P and Clynes D: A glimpse into the epigenetic landscape of gene regulation. Curr Opin Genet Dev 18: 116-122, 2008.

15. Grewal SI and Elgin SC: Transcription and RNA interference in the formation of heterochromatin. Nature 447: 399-406, 2007.

16. Reik W: Stability and flexibility of epigenetic gene regulation in mammalian development. Nature 447: 425-432, 2007.

17. Tchurikov NA: Molecular mechanisms of epigenetics. Biochemistry (Mosc) 70: 406-423, 2005.

18. Zaratiegui M, Irvine DV and Martienssen RA: Noncoding RNAs and gene silencing. Cell 128: 763-776, 2007.

19. Ponting CP, Oliver PL and Reik W: Evolution and functions of long noncoding RNAs. Cell 136: 629-641, 2009.

20. Costa FF: Non-coding RNAs, epigenetics and complexity. Gene 410: 9-17, 2008.

21. Amaral PP, Dinger ME, Mercer TR and Mattick JS: The eukaryotic genome as an RNA machine. Science 319: 1787-1789, 2008.

22. Ghildiyal $M$ and Zamore PD: Small silencing RNAs: An expanding universe. Nat Rev Genet 10: 94-108, 2009.

23. Yu H: Epigenetics: Advances of non-coding RNAs regulation in mammalian cells. Yi Chuan 31: 1077-1086, 2009 (In Chinese).

24. Moazed D: Small RNAs in transcriptional gene silencing and genome defence. Nature 457: 413-420, 2009.

25. Jinek $M$ and Doudna JA: A three-dimensional view of the molecular machinery of RNA interference. Nature 457: 405-412, 2009. 
26. Morris KV, Chan SW, Jacobsen SE and Looney DJ: Small interfering RNA-induced transcriptional gene silencing in human cells. Science 305: 1289-1292, 2004.

27. Kawasaki $\mathrm{H}$ and Taira K: Induction of DNA methylation and gene silencing by short interfering RNAs in human cells. Nature 431: 211-217, 2004.

28. Bayne EH and Allshire RC: RNA-directed transcriptional gene silencing in mammals. Trends Genet 21: 370-373, 2005.

29. Zhou W, Wang J, Man WY, Zhang QW and Xu WG: siRNA silencing EZH2 reverses cisplatin-resistance of human non-small cell lung and gastric cancer cells. Asian Pac J Cancer Prev 16 2425-2430, 2015.

30. Viré E, Brenner C, Deplus R, Blanchon L, Fraga M, Didelot C, Morey L, Van Eynde A, Bernard D, Vanderwinden JM, et al: The Polycomb group protein EZH2 directly controls DNA methylation. Nature 439: 871-874, 2006.

31. Hall IM, Shankaranarayana GD, Noma K, Ayoub N, Cohen A and Grewal SI: Establishment and maintenance of a heterochromatin domain. Science 297: 2232-2237, 2002.

32. Volpe TA, Kidner C, Hall IM, Teng G, Grewal SI and Martienssen RA: Regulation of heterochromatic silencing and histone H3 lysine-9 methylation by RNAi. Science 297 : 1833-1837, 2002

33. Chen S, He H and Deng X: Allele-specific DNA methylation analyses associated with siRNAs in Arabidopsis hybrids. Sci China Life Sci 57: 519-525, 2014.

34. Zilberman D, Cao X and Jacobsen SE: ARGONAUTE4 control of locus-specific siRNA accumulation and DNA and histone methylation. Science 299: 716-719, 2003.

35. Maison C, Bailly D, Peters AH, Quivy JP, Roche D, Taddei A, Lachner M, Jenuwein T and Almouzni G: Higher-order structure in pericentric heterochromatin involves a distinct pattern of histone modification and an RNA component. Nat Genet 30: 329-334, 2002

36. Lippman Z, Gendrel AV, Black M, Vaughn MW, Dedhia N, McCombie WR, Lavine K, Mittal V, May B, Kasschau KD, et al: Role of transposable elements in heterochromatin and epigenetic control. Nature 430: 471-476, 2004.

37. Ruvkun G: Molecular biology. Glimpses of a tiny RNA world. Science 294: 797-799, 2001.

38. Carthew RW and Sontheimer EJ: Origins and mechanisms of miRNAs and siRNAs. Cell 136: 642-655, 2009.

39. Luo M, Hao L, Hu F, Dong Y, Gou L, Zhang W, Wang X, Zhao Y, Jia M, Hu S, et al: MicroRNA profiles and potential regulatory pattern during the early stage of spermatogenesis in mice. Sci China Life Sci 58: 442-450, 2015.

40. Kozomara A and Griffiths-Jones S: miRBase: Annotating high confidence microRNAs using deep sequencing data. Nucleic Acids Res 42 (D1): D68-D73, 2014.

41. Griffiths-Jones S, Grocock RJ, van Dongen S, Bateman A and Enright AJ: miRBase: microRNA sequences, targets and gene nomenclature. Nucleic Acids Res 34: D140-D144, 2006.

42. Bartel DP: MicroRNAs: Target recognition and regulatory functions. Cell 136: 215-233, 2009.

43. Rajewsky N: microRNA target predictions in animals. Nat Genet 38 (Suppl): S8-S13, 2006.

44. Lewis BP, Burge CB and Bartel DP: Conserved seed pairing, often flanked by adenosines, indicates that thousands of human genes are microRNA targets. Cell 120: 15-20, 2005.

45. Denis H, Ndlovu MN and Fuks F: Regulation of mammalian DNA methyltransferases: A route to new mechanisms. EMBO Rep 12: 647-656, 2011.

46. Yuan JH, Yang F, Chen BF, Lu Z, Huo XS, Zhou WP, Wang F and Sun SH: The histone deacetylase 4/SP1/microRNA-200a regulatory network contributes to aberrant histone acetylation in hepatocellular carcinoma. Hepatology 54: 2025-2035, 2011.

47. Tuddenham L, Wheeler G, Ntounia-Fousara S, Waters J, Hajihosseini MK, Clark I and Dalmay T: The cartilage specific microRNA-140 targets histone deacetylase 4 in mouse cells. FEBS Lett 580: 4214-4217, 2006.

48. Kim DH, Saetrom P, Snøve O Jr and Rossi JJ: MicroRNAdirected transcriptional gene silencing in mammalian cells. Proc Natl Acad Sci USA 105: 16230-16235, 2008.

49. Khraiwesh B, Arif MA, Seumel GI, Ossowski S, Weigel D, Reski R and Frank W: Transcriptional control of gene expression by microRNAs. Cell 140: 111-122, 2010.

50. Wu L, Zhou H, Zhang Q, Zhang J, Ni F, Liu C and Qi Y: DNA methylation mediated by a microRNA pathway. Mol Cell 38: $465-475,2010$
51. Fabbri M, Garzon R, Cimmino A, Liu Z, Zanesi N, Callegari E, Liu S, Alder H, Costinean S, Fernandez-Cymering C, et al: MicroRNA-29 family reverts aberrant methylation in lung cancer by targeting DNA methyltransferases $3 \mathrm{~A}$ and 3B. Proc Natl Acad Sci USA 104: 15805-15810, 2007.

52. Benetti R, Gonzalo S, Jaco I, Muñoz P, Gonzalez S, Schoeftner S, Murchison E, Andl T, Chen T, Klatt P, et al: A mammalian microRNA cluster controls DNA methylation and telomere recombination via Rbl2-dependent regulation of DNA methyltransferases. Nat Struct Mol Biol 15: 998, 2008.

53. Sinkkonen L, Hugenschmidt T, Berninger P, Gaidatzis D, Mohn F, Artus-Revel CG, Zavolan M, Svoboda P and Filipowicz W: MicroRNAs control de novo DNA methylation through regulation of transcriptional repressors in mouse embryonic stem cells. Nat Struct Mol Biol 15: 259-267, 2008.

54. Gonzalez S, Pisano DG and Serrano M: Mechanistic principles of chromatin remodeling guided by siRNAs and miRNAs. Cell Cycle 7: 2601-2608, 2008.

55. Lau NC, Seto AG, Kim J, Kuramochi-Miyagawa S, Nakano T, Bartel DP and Kingston RE: Characterization of the piRNA complex from rat testes. Science 313: 363-367, 2006.

56. Grivna ST, Beyret E, Wang Z and Lin H: A novel class of small RNAs in mouse spermatogenic cells. Genes Dev 20: 1709-1714, 2006.

57. Lin H: piRNAs in the germ line. Science 316: 397, 2007.

58. Aravin AA, Sachidanandam R, Bourc'his D, Schaefer C, Pezic D, Toth KF, Bestor T and Hannon GJ: A piRNA pathway primed by individual transposons is linked to de novo DNA methylation in mice. Mol Cell 31: 785-799, 2008.

59. Aravin AA, Hannon GJ and Brennecke J: The Piwi-piRNA pathway provides an adaptive defense in the transposon arms race. Science 318: 761-764, 2007.

60. Houwing S, Kamminga LM, Berezikov E, Cronembold D, Girard A, van den Elst H, Filippov DV, Blaser H, Raz E, Moens CB, et al: A role for Piwi and piRNAs in germ cell maintenance and transposon silencing in Zebrafish. Cell 129: 69-82, 2007.

61. Yin $\mathrm{H}$ and Lin $\mathrm{H}$ : An epigenetic activation role of Piwi and a Piwi-associated piRNA in Drosophila melanogaster. Nature 450: 304-308, 2007.

62. Huang XA, Yin H, Sweeney S, Raha D, Snyder M and Lin H: A major epigenetic programming mechanism guided by piRNAs. Dev Cell 24: 502-516, 2013.

63. Bourc'his D and Bestor TH: Meiotic catastrophe and retrotransposon reactivation in male germ cells lacking Dnmt3L. Nature 431: 96-99, 2004.

64. Kuramochi-Miyagawa S, Watanabe T, Gotoh K, Totoki Y, Toyoda A, Ikawa M, Asada N, Kojima K, Yamaguchi Y, Ijiri TW, et al: DNA methylation of retrotransposon genes is regulated by Piwi family members MILI and MIWI2 in murine fetal testes. Genes Dev 22: 908-917, 2008.

65. Cao X, Yeo G, Muotri AR, Kuwabara T and Gage FH: Noncoding RNAs in the mammalian central nervous system. Annu Rev Neurosci 29: 77-103, 2006.

66. Mercer TR, Dinger ME and Mattick JS: Long non-coding RNAs: Insights into functions. Nat Rev Genet 10: 155-159, 2009.

67. Wang KC and Chang HY: Molecular mechanisms of long noncoding RNAs. Mol Cell 43: 904-914, 2011.

68. Yang PK and Kuroda MI: Noncoding RNAs and intranuclear positioning in monoallelic gene expression. Cell 128: 777-786, 2007.

69. Cai X and Cullen BR: The imprinted H19 noncoding RNA is a primary microRNA precursor. RNA 13: 313-316, 2007.

70. Wu HA and Bernstein E: Partners in imprinting: Noncoding RNA and polycomb group proteins. Dev Cell 15: 637-638, 2008.

71. Pandey RR, Mondal T, Mohammad F, Enroth S, Redrup L, Komorowski J, Nagano T, Mancini-Dinardo D and Kanduri C: Kcnq1ot1 antisense noncoding RNA mediates lineage-specific transcriptional silencing through chromatin-level regulation. Mol Cell 32: 232-246, 2008.

72. Regha K, Sloane MA, Huang R, Pauler FM, Warczok KE, Melikant B, Radolf M, Martens JH, Schotta G, Jenuwein T, et al: Active and repressive chromatin are interspersed without spreading in an imprinted gene cluster in the mammalian genome. Mol Cell 27: 353-366, 2007.

73. Clemson CM, McNeil JA, Willard HF and Lawrence JB: XIST RNA paints the inactive $X$ chromosome at interphase: Evidence for a novel RNA involved in nuclear/chromosome structure. J Cell Biol 132: 259-275, 1996. 
74. Zhao J, Sun BK, Erwin JA, Song JJ and Lee JT: Polycomb proteins targeted by a short repeat RNA to the mouse X chromosome. Science 322: 750-756, 2008.

75. Zhou X, Ren Y, Zhang J, Zhang C, Zhang K, Han L, Kong L, Wei J, Chen L, Yang J, et al: HOTAIR is a therapeutic target in glioblastoma. Oncotarget 6: 8353-8365, 2015.

76. Zhang K, Sun X, Zhou X, Han L, Chen L, Shi Z, Zhang A, Ye M, Wang Q, Liu C, et al: Long non-coding RNA HOTAIR promotes glioblastoma cell cycle progression in an EZH2 dependent manner. Oncotarget 6: 537-546, 2015.
77. Rinn JL, Kertesz M, Wang JK, Squazzo SL, Xu X, Brugmann SA, Goodnough LH, Helms JA, Farnham PJ, Segal E, et al: Functional demarcation of active and silent chromatin domains in human HOX loci by noncoding RNAs. Cell 129: 1311-1323, 2007.

78. Ogawa Y, Sun BK and Lee JT: Intersection of the RNA interference and X-inactivation pathways. Science 320: 1336-1341, 2008. 